\title{
Research on Regional Strategic Emerging Industry Selection Models Based on Fuzzy Optimization and Entropy Evaluation
}

\author{
Xiuying Guo ${ }^{1,2}$ and Xiaofeng Hui ${ }^{1}$ \\ ${ }^{1}$ College of Management, Harbin Institute of Technology, Harbin, Heilongjiang 150001, China \\ ${ }^{2}$ College of Mathematics, Heilongjiang Institute of Technology, Harbin, Heilongjiang 150050, China \\ Correspondence should be addressed to Xiuying Guo, guoxiuying6@163.com
}

Received 17 September 2012; Accepted 20 November 2012

Academic Editor: Jian-Wen Peng

Copyright (C) 2012 X. Guo and X. Hui. This is an open access article distributed under the Creative Commons Attribution License, which permits unrestricted use, distribution, and reproduction in any medium, provided the original work is properly cited.

It is with a great significance to discuss the selection model of regional strategic emerging industry. First, the paper uses the fuzzy optimization theory to select the central industry of area as the regional strategic emerging industry and try to optimize the weight's calculation in the multistage fuzzy comprehensive evaluation to get more accurate results. Then it will do a strategic emerging industrial inspection about the advantage and ecological related index based on a multiobjective programming model and the maximum entropy.

\section{Introduction}

Strategic emerging industry includes both the characteristics of the huge development potential and the strong leading ability as strategic industry and the highly innovative characteristics as emerging industry. After the financial crisis period, countries all over the world especially some major developed countries take the development of new energy, new materials, energy conservation and environmental protection, and green economy emerging industry as a key of a new round of industry development. In September 2009, China first raised the concept of strategic emerging industry and selected seven industries as the national strategic emerging industries.

At present the provinces in our country also take a national strategic emerging industry planning as a guide and put forward the strategic emerging industry which will be developed in this area. Making a strategic arrangement in the development of 
national strategic emerging industry in 30 provinces of our country, we found that the choice of a regional strategic new industry convergence was serious that the choice of the new material area should achieve 29, new energy 26, and the choice of biological 25 . But the regional industry structure characteristics and resources endowment difference are not taken into consideration, which will inevitably lead to three prominent problems that are serious industry homogenization phenomenon, excess capacity, and the waste of resources. Therefore, how to scientifically choose accurate selection and evaluation of regional strategic emerging industry is of a strong theoretical and practical significance.

\section{Literature Review}

The American economists Hector Seaman (A. O. Hirschman), the first person to put forward the concept of strategic industry, has called the put-output relationship between the most closely related economic system "strategic department" [1]. Cambridge scholars such as Heffeman have carried on a deep analysis of the emerging industry characteristics, development, evolution path system, and so on. From the perspective of commercial development, it emphasizes on the idea-to-product of the conversion process, and that emerging industry development is a dynamic evolution process [2]. Liu from strategic emerging industry concept holds that the strategic emerging industry has at least several characteristics such as strategy, innovation, growth, relevance, guidance, and risk [3]. Some researchers have a try on the choice of strategic emerging industry. Hu and Zhao of Liaoning province evaluated 18 scales above high and new technology industrial economic benefits in 2006, using factor analysis, and got development strategic emerging industry potential and comparative advantage of industry [4]. He et al. [5-7] established the evaluation model based on analytic hierarchy process (AHP) and integrated fuzzy evaluation method, and they knew about a region that was whether or not fit for the development of strategic new industry by the model. and helped the region to have comprehensive, accurate, and objective selection and evaluation of strategic emerging industry. Qing [8], with the aid of expert questionnaire marking method and analytic hierarchy process (AHP), calculated the weights of the six factors such as natural, economic, social and human, science and technology, industrial competitiveness, and the government which had influenced the emerging industry development in Henan province and put in order the seven big emerging industry developments according to quality. Qiao et al., [9] based on the gray theory analysis, established the evaluation index system and evaluation mode 1 which are suited to the characteristics of the strategic emerging industry in biological medicine. Hu et al., [10] based on the combination weights "AHP-IE-PCA", the selection model of regional strategic emerging industries was tentative proposed, which was applied to $\mathrm{N}$ county in the selection and evaluation of strategic emerging industries.

It is obvious that, at present, the empirical research of regional strategic emerging industry choice always uses the analytic hierarchy process and expert scoring method, and this kind of method subjectivity is too strong and lacks dynamics. In addition the choice of empirical research is more than an unidirectional choice, and the lack of the selected conclusion effectiveness and efficiency evaluation makes the industry choice lack research reliability analysis and policy persuasion.

Vector optimization ideas originated from utility theory research in economics from 1776. In 1896, French economist Pareto [11] first put forward the problem of the multiobjective programming for a limited number of evaluation index in economic balance study. 
At that time, from the perspective of political economics, he summarized a lot of targets difficult to compare as multi-objective optimization and proposed the thought of the later called Pareto efficient solution, and this thought had an important and profound impact upon the forming of the vector optimization disciplines. In 1944, from the point of view of game theory, Neumann and Morgenstern [12] put forward the problem of multi-objective decision which contradicted each other and had several decision makers. In 1951, from the analysis of production and distribution activities, Koopmans [13] put forward the problem of multi-objective optimization, and for the first time he put forwards the concept of Pareto effective solution. In the same year, from the point of view of mathematical programming, Kuhn and Tucker [14] proposed the concept of Pareto efficient solution for the vector extremism and studied this solution's optimally sufficient and necessary conditions. The evaluation balanced research by Debreu [15] in 1954, the research of pushing multi-objective optimization problem to the general topological vector space by Harwicz [16] in 1958, and the vector optimization problems were concerned by people gradually. In 1968, Johnsen [17] published the first monograph about multi-objective decision-making model. In 1970 Bellman and Zadeh put forward "fuzzy optimization" concept and provided effective tool for linear programming in several fields which had more fuzzy factors, such as multi-objective optimization [18].

Therefore, with the aid of the industrial structure similarity coefficient, this paper will first measure the area of industrial isomorphism, thus give system dynamical judgment of the regional industrial structure convergence change characteristics, and determine the regional industrial structure from the macroscopic perspective preliminary. Secondly, in view of regional strategic emerging industry, selection is influenced by multiple factors and belongs to multistage comprehensive evaluation problem, the paper uses the method of fuzzy mathematics comprehensive evaluation. Since it is needed to optimize and improve multistage fuzzy comprehensive evaluation model, the evaluation results will be as accurate and objective as possible. Finally, the paper will evaluate the chosen results and calculate the quotient of location to find out whether the area industry has advantage in the same industry of country or not. It will calculate intersection to the two kinds of industry and confirm the area strategic emerging industry. In addition, it will be coupled to an evaluation about the traditional industries and the strategic emerging industries, including double coupling relevance and developmental evaluation.

\section{The Selection Model of Strategic Emerging Industries}

\subsection{Regional Industrial Structure Convergence Degree Test}

Firstly the research is to analyze the convergence of industrial structure, and carry on the measure. The convergence of industrial structure generally refers to a phenomenon that the areas of different geographical location, different resource abundance and different development path form a similar industrial structure, which refers in particular to the convergence within the industry and the internal structure of industry. The convergence of industrial structure mainly performances for the structure of the industry between the areas difference contractible, industrial categories and industrial systems between the areas resembling gradually, spatial distribution equalization of the major industries and product production. As to the specific measure of industrial isomorphism, this paper uses the similarity coefficient method put forward by the United Nations industrial development 
organization international industrial research center and Shingling Wang's related research; the similarity coefficient is defined as [19]:

$$
S_{i j}=\frac{\sum_{k=1}^{n} X_{i k} \cdot \sum_{j=1}^{n} X_{j k}}{\sqrt{\sum_{k=1}^{n} X_{i k}^{2} \cdot \sum_{k=1}^{n} X_{j k}^{2}}} .
$$

The type of $S_{i j}$ is similarily coefficient, $I, j$ is two phase comparison areas, and $X_{i k}$, $X_{j k}$ are industries $k$ in the area $I$ and $j$ region as a proportion of the industrial structure. $S_{i j}$ is a direct link between the number of 0 and 1 . And if the value is 0 , it means the two compared regional industrial structures are completely different; if the value is 1 , it means the two compared regional manufacturing structures are exactly the same. Through the observation of the certain period $S_{i j}$ value changes, it may give dynamic judgments to the changes in regional industrial structure. If $S_{i j}$ value tends to rise, it is "structure convergence"; if $S_{i j}$ value tends to decline, it is "structure divergence." In this way, it can judge on the whole the similar degree of different regional industrial structure so as to provide macro basis for a strategic choice of emerging industry.

\subsection{Multistep Fuzzy Comprehensive Evaluation Model}

Multistage fuzzy comprehensive evaluation model is the organic union of multistage fuzzy theory and classic comprehensive evaluation method, which is mainly used to solve the evaluation object affected by various uncertain factors and the various factors, and has different levels. The choice of strategic emerging industry involves many fuzzy factors, and various factors have obvious hierarchy; therefore, we will choose the multistage fuzzy comprehensive evaluation method to research it. In the fuzzy comprehensive evaluation model, establishing single factor evaluation matrix $R$ and determining the weight distribution $A$ are two key jobs. But at the same time there is no unified format which can be abided by. Typically it uses the expert evaluation method to work out, but in practical operation this kind of method has weakness in the long survey period, which may delay decision time and affect the real-time performance of the evaluation results to a certain extent. Here the paper will mainly discuss how to use the statistical method to determine the weights model.

The strategic emerging industry index system is as shown in Figure 1.

\subsubsection{The Fuzzy Weighted Vector Sure [20]}

Multistage fuzzy comprehensive evaluation method often uses Delphi method to determine the index weight, which affects the model practicality and objectivity of evaluation results. In order to overcome this shortcoming of this model, we will determine the weight of each index by the variation coefficient method. First, through the Figure 1 index system, determine the level one evaluation index set $U=\left\{u_{1}, u_{2}, \ldots, u_{n}\right\} ; u_{i}$ means the $i$ th one class index. Second, we will further divide it into several evaluation levels according to the assessment and evaluation factors: $u_{i j}=\left\{u_{j 1}^{\prime}, u_{j 2}^{\prime}, \ldots, u_{j k}^{\prime}\right\} ; k$ is the number of evaluation factors for the $i$ th evaluation, the $j$ th evaluation factor. Third, using variance method to determine the weight 


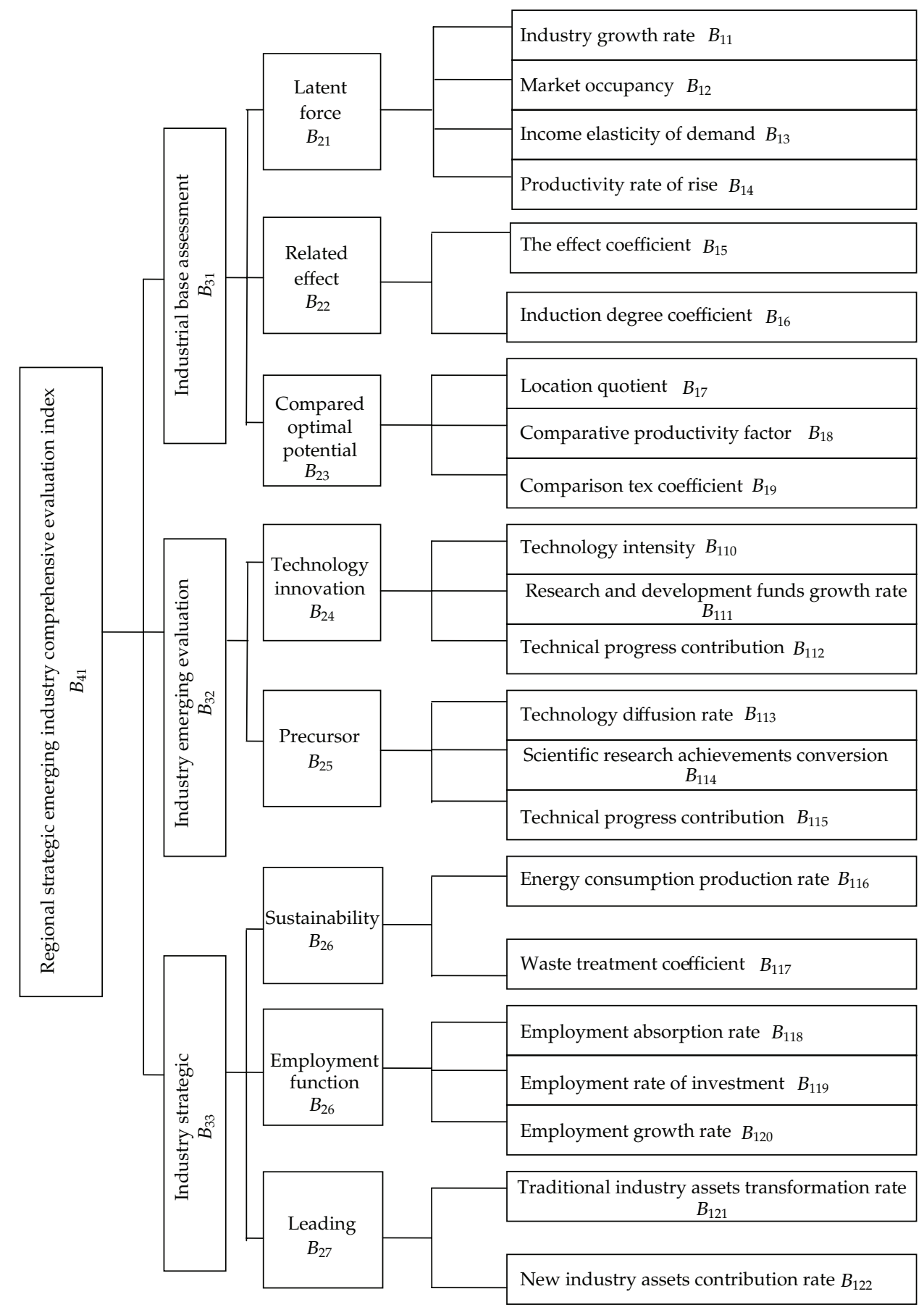

Level 4 evaluation Level 3 evaluation Level 2 evaluation

Level 1 evaluation

Figure 1: Index system of regional strategic emerging industry. 
of each basic index $A$ reflects the importance of the various factors in the whole. That is, each index is $A$ group of survey data $z_{1}, z_{2}, \ldots, z_{n}$, written as

$$
\begin{gathered}
\bar{z}=\frac{1}{n} \sum_{i=1}^{n} x_{i} \\
t_{k}=\left(\frac{1}{n-1} \sum_{i=1}^{n}\left(z_{i}-\bar{z}\right)^{2}\right)^{1 / 2}
\end{gathered}
$$

That is

$$
v_{k}=\frac{t_{k}}{|\bar{z}|}
$$

$v_{k}$ is the coefficient of the variation of data $z_{1}, z_{2}, \ldots, z_{n}$, the weight $a_{j}$ is:

$$
a_{j}=\frac{v_{j}}{\sum_{i=1}^{m} v_{i}}
$$

\subsubsection{Comment Set and the Determination of Membership Function}

Be sure that comment set $U=\{$ shall not choose, will consider, should select $\}$ and membership functions in order to determine the evaluation factors on the comments membership.

\subsubsection{The Generation of Fuzzy Judgment Vector B [21]}

Starting from the $U_{i}$, determining the evaluation object of evaluation element set $v$ and degrees of membership $R_{i}$ is, namely, called single factor fuzzy evaluation. Factor $U_{i}$ and evaluation results $R_{i}$ are called single factor fuzzy evaluation set, which is the $v$ fuzzy subset, $R_{i}=\left\{r_{i 1}, r_{i 2}, \ldots, r_{i m}\right\}$.

Put the single factor evaluation set as the line, then it can get deviation fuzzy matrix:

$$
R=\left[\begin{array}{llll}
r_{11} & r_{12} & \cdots & r_{1 m} \\
\cdots & \cdots & \cdots & \cdots \\
r_{n 1} & r_{n 2} & \cdots & r_{n m}
\end{array}\right]
$$

In type (3.4),

$$
r_{i j}=\frac{\left|a_{i j}-\lambda_{i}\right|}{\max \left\{a_{i j}\right\}-\min \left\{a_{i j}\right\}}, \quad \lambda_{i}=\left\{\begin{array}{c}
\max \left\{a_{i j}\right\}, a_{i j} \text { is performance indicator, } \\
\min \left\{a_{i j}\right\}, a_{i j} \text { is cost indicator. }
\end{array}\right.
$$


Single factor fuzzy evaluation can only reflect a factor of evaluation object, but cannot reflect the comprehensive influence of all factors. Thus, all factors must be comprehensively considered. All single factor fuzzy evaluation can be expressed as

$$
\begin{gathered}
B=A \cdot R=\left(a_{1}, a_{2}, \ldots, a_{n}\right)\left[\begin{array}{cccc}
r_{11} & r_{12} & \cdots & r_{1 m} \\
\cdots & \cdots & \cdots & \cdots \\
r_{n 1} & r_{n 2} & \cdots & r_{n m}
\end{array}\right]=\left(b_{1}, b_{2}, \ldots, b_{n}\right), \\
b_{i}=\bigvee_{i=1}^{n}\left(a_{i} \wedge r_{i j}\right), \quad j=1,2, \ldots, m .
\end{gathered}
$$

In formula (3.7), " $\wedge$ " and " $\vee$ " are "take small" operator, "take big" operator.

\subsubsection{Construct an Evaluation Function}

In order to facilitate and get an accurate evaluation result, suppose the level of the value of a variable range is 0-60 (not to be chosen), 60-80 (to be considered), and 80-100 (should be chosen) and calculate the group data to get evaluation matrix $P$ :

$$
P=\left[\begin{array}{l}
50 \\
70 \\
90
\end{array}\right] \text {. }
$$

Then the comprehensive evaluation function is

$$
S=B \cdot R
$$

Then according to the size of the $S$, Table 1 found out the corresponding level evaluation, which is the final evaluation result of whether the strategic emerging industry has been chosen or not.

\subsection{Fuzzy Evaluation Model Optimization}

\subsubsection{Optimization of Multistage Fuzzy Comprehensive Evaluation Methods [20]}

Because the evaluation vector is at the next higher level for the fuzzy evaluation vector, it can use the level evaluation of fuzzy evaluation vector to structure the evaluation fuzzy evaluation set again. In addition, another important problem is to determine the index weight above Level two. As the variation coefficient method applies only to statistical index, and the indicators above Level two have no direct statistics, the paper will adjust the above evaluation method so that researchers can use the statistical method to calculate the weight of the index above the second level.

After the calculation of the level of the index weight, we separately judge each questionnaire for the primary evaluation, get the fuzzy evaluation vector of secondary evaluation index $\left(y_{1}, y_{2}, \ldots, y_{n}\right)$, use the membership functions of inverse function to calculate secondary statistical indexes $x_{2 i}$, put each index value of the questionnaire 
Table 1: Comparison between the results of evaluation and the level of remark.

\begin{tabular}{lccc}
\hline Level comments & Not chosen & To be considered & Should be chosen \\
The comprehensive evaluation value & {$[0,60]$} & {$[60,80]$} & {$[80,100]$} \\
\hline
\end{tabular}

calculated as a secondary index of the statistics, and repeat the process of the different coefficient method to determine the secondary index weight. The index weights above the second level are calculated with this method. Then repeat the above steps so as to complete the fuzzy comprehensive evaluation of each layer index.

\subsubsection{Optimization of the Weights in the Fuzzy Comprehensive Evaluation [22]}

Objective weighting method is got according to current sample data statistics, related to weight and the current sample data, which has a stronger objectivity and avoids the deviation of the artificial factors. It also has the determination of the weight of the consideration on each factor, such as principal component analysis focused on the relationship between index data, the mean square error method, maximizing deviations method, the entropy weight method, and the variation coefficient method. All of them have more consideration of the influence of the data discrete sex to the real evaluation result. Therefore there is also likely the situation in disagreement with the importance of the determination between the weight of index and the index itself.

Therefore, this paper will optimize the method of the fuzzy comprehensive evaluation weights calculation, combine the principal component analysis method and the entropy weighting method of mutual confluence, so that it can keep both the principal component analysis and the linear combination of the original data, simplify the advantages of the index, and at the same time compensate the defect without the consideration of the principal component analysis and the determination of the weights for data features by means of entropy value method. The concrete methods are as follow.

(1) Make the original data of $n$ industry $p$ indexes matrix $X(i=1,2, \ldots, n ; j=$ $1,2, \ldots, p)$, which were then dimensionless or standardized processing and generally use Z-score method, which is dimensionless, and next get new $M_{i j}$ matrix.

(2) The correlation coefficient matrix $R_{j k}$ of the calculation index:

$$
R_{j k}=\frac{1}{n} \cdot \sum_{i=1}^{n} \frac{\left(X_{i j}-\overline{X_{j}}\right)}{S_{j}} \cdot \frac{\left(X_{i k}-\overline{X_{k}}\right)}{S_{k}}=\frac{1}{n} \sum_{i=1}^{n} Z_{i j} \cdot Z_{i k}, \quad R_{j j}=1, R_{j k}=R_{k j}
$$

(3) Work out the $R_{j k}$ array value of characteristics $\lambda_{k}(k=1,2, \ldots, p)$ and characteristic vector $L_{k}(k=1,2, \ldots, p)$. According to the characteristic equation:

$$
|R-\lambda I|=0 .
$$

Calculate characteristic value $\lambda_{k}$, citing the characteristic value $\lambda_{k}$, and feature vector $L_{k}$. 
(4) Calculation of contribution rate:

$$
T_{k}=\frac{\lambda_{k}}{\sum_{j=1}^{p} \lambda_{j}}
$$

and cumulative contribution:

$$
D_{k}=\sum_{j=1}^{k} T_{j} .
$$

The selection of $D_{m} \geq 85 \%$ of the characteristic value $\lambda_{m}(m<p)$ corresponding several principal components.

(5) Use each principal component proportion of the principal components to explain reflects index righteousness.

(6) Calculate the principal component index weights. The first $m$ a principal component characteristic value of the product contribution $D_{m}$ is set 1 . Calculate the $T_{1}, T_{2}, \ldots, T_{m}$ of the corresponding new $T_{1}^{\prime}, T_{2}^{\prime}, \ldots, T_{m}^{\prime}$, that is, the main component of the index weights.

(7) Calculate the principal components and get part matrix $F_{i j}(i=1,2, \ldots, m ; j=$ $1,2, \ldots, n)$. So far, we have achieved the purpose of simplified index number with the aid of the principal component analysis method. Next we will use entropy weight method to calculate the weight of each index factor.

(8) Data translation. Make

$$
y_{i j}=y_{i j}+1 \quad(i=1,2, \ldots, m ; j=1,2, \ldots, n) .
$$

Because using entropy value to work out weight should be made use of logarithmic calculation, in this way we can avoid taking logarithmic time nonsense.

(9) Calculating the proportion of the index in the $j$ indexes and $i$ the value of the industry:

$$
P_{i j}=\frac{y_{i j}}{\sum_{i=1}^{m} y_{i j}} \quad(i=1,2, \ldots, m ; j=1,2, \ldots, n) .
$$

(10) Computing the first $j$ indexes entropy:

$$
e_{j}=-k \sum_{i=1}^{m} P_{i j} \ln P_{i j}, \quad k>0, k=\frac{1}{\ln (n)}, e_{j} \geq 0
$$

(11) Compute the difference coefficient of the $j$ indexes. As to the $j$ indexes, the greater the differences of the $Y_{i j}$ index value is, the greater effect the scheme evaluation $Y_{i j}$ 
is and the smaller the entropy value is. The definition of the difference coefficient is as follows:

$$
g_{i}=\frac{1-e_{j}}{\sum_{j=1}^{n}\left(1-e_{j}\right)}=\frac{1-e_{j}}{n-E_{e}}, \quad E=\sum_{j=1}^{n} e_{j}, 0 \leq g_{i} \leq 1, \sum_{j=1}^{n} g_{j}=1
$$

(12) Working out weight:

$$
w_{j}=\frac{g_{j}}{\sum_{j=1}^{n} g_{j}} \quad(1 \leq j \leq n)
$$

(13) Weighted comprehensive evaluation model according to many indexes to calculate the comprehensive evaluation value:

$$
S_{i}=\sum_{j=1}^{m} w_{j} \cdot P_{i j} \quad(i=1,2 \ldots m ; j=1,2 \ldots n) .
$$

\section{The Inspection Model Strategic Emerging Industries}

\subsection{The Industry Advantage Index}

\subsubsection{The Escalating Rate of Productivity Index}

As a strategic emerging industry, the high escalating rate of productivity has a high potential for growth and development advantages, and such ability will drive the development of the industry system. The escalating rate of productivity index,

$$
v_{i}=\frac{a_{i}\left(t_{n}\right)-a_{i}\left(t_{0}\right)}{t_{n}-t_{0}} .
$$

$a_{i}\left(t_{n}\right)$ is the productivity of theith sector and the $t_{n}$ year, $a_{i}\left(t_{0}\right)$ is the productivity of theith sector and the $t_{0}$ year.

\subsubsection{The Comparative Advantage Coefficient}

The selection of strategic emerging industry should be beneficial in this area's development, and should have a certain comparative advantage in the output value, profit tax rate, and so forth. The relative advantage of $i$ th sector will be shown $\eta_{i}$,

$$
\eta_{i}=\frac{x_{i} / x}{X_{i} / X} \cdot \frac{o_{i} / o}{O_{i} / O} \cdot \frac{p_{i} / p}{P_{i} / P} \cdot \frac{t_{i}}{T_{i}} \cdot \frac{q_{i}}{Q_{i}} .
$$

$x_{i}, o_{i}, p_{i}$ and $t_{i}$ are, respectively, the product value, product output, total factor productivity, and profit tax rate of the $i$ th sector; $q_{i}$ is the year-end staff's total of $i$ industry 
departments; $x, o$, and $p$ are, respectively, total product value, total value of product output, and average productivity of each sector; $Q_{i}$ is the year-beginning staff's total of $i$ industry departments; $X_{i}, O_{i}, P_{i}$, and $T_{i}$ are, respectively, total product value, product output, total factor productivity, and profit tax rate of the $i$ sector; $X, O$, and $P$ are, respectively, total product value, total value of product output, total profit tax rate. $Q$ is average productivity of all of sectors.

\subsection{The Industry Lead Function Index}

\subsubsection{The Technology Index}

Strategic emerging industry has a new technical support, such as the capital fusion, science and technology innovation, and talent cultivation that will focus on the industry. One has

$$
\pi_{i}=\frac{v_{i}}{\left[y_{i}\left(t_{n}\right)-y_{i}\left(t_{0}\right)\right] /\left(t_{n}-t_{0}\right)} \cdot \frac{x_{i}}{X_{i}} \cdot \frac{\omega_{i}}{y_{i}}
$$

$v_{i}$ is the improved rate of productivity, $y_{i}\left(t_{n}\right)$-is the total product value of the $i$ th sector in the $i$ th year, $x_{i}$-is total technology personnel of the $i$ th sector, $X_{i}$-is total employment personnel of the $i$ th sector, and $\omega_{i}$ is $R \& D$ funds.

\subsubsection{The Location Entropy}

Location entropy coefficient compares the specialized level of area industrial department with the average level of one country. It can evaluate the competitive level of an area strategic emerging industry in the country. One has

$$
L Q=\frac{y_{i} / y}{Y_{i} / Y}
$$

\subsection{The Industry Ecosystem Index}

\subsubsection{The Output Value Rate of Unit Energy Index}

The output value rate of unit energy reflects the industry department energy dissipation capacity, and the strategic emerging industry should be the low consumption industry. One has

$$
h_{i}=\frac{y_{i}}{\sum_{j=1}^{n_{2}} e_{i j} \times f_{2 j}} .
$$

$e_{i j}$ is the total of $j$ energy utilized by $i$ sector; $f_{2 j}$ is the use of the fees of unit $j$ energy; $n_{2}$ is the type of energy. 


\subsubsection{The Output Value Rate of Unit Three-Kinds-Waste Discharge Index}

One has

$$
g_{i}=\frac{y_{i}}{\sum_{j=1}^{3} w_{i j} \times f_{1 j}}
$$

$w_{i j}$ is the total of $j$ waste outputted by $i$ sector; $f_{1 j}$ is the administered fees of unit $j$ waste.

\subsection{The Selection Model of the Maximum Entropy}

\subsubsection{Establish Evaluation Matrix}

Definition 4.1. Suppose there is $n$ industry to participate in the selection, notes for $Q=$ $\left\{Q_{1}, Q_{2}, Q_{3}, \ldots, Q_{n}\right\}$, the number of each industry evaluation index is $m$; notes for $P=$ $\left\{P_{1}, P_{2}, P_{3}, \ldots, P_{m}\right\}, x_{i j}$ is the evaluation value of the $i$ th industry and the $j$ th evaluation index. $A=\left[x_{i j}\right]_{n \times m}$ is the evaluation matrix of industry set $Q$ for index set $P$ :

$$
A=\left|\begin{array}{cccc}
x_{11} & x_{12} & \cdots & x_{1 m} \\
x_{21} & x_{22} & \cdots & x_{2 m} \\
\cdots & \cdots & \cdots & \cdots \\
x_{n 1} & x_{n 2} & \cdots & x_{n m}
\end{array}\right| .
$$

Presume standard index:

$$
x_{0 j}=\frac{1}{n} \sum_{i=1}^{n} x_{i j}
$$

Let the $j$ th index $\left(x_{1 j}, x_{2 j}, \ldots, x_{n j}\right)$ compare with standard index, determine its corresponding equivalent value $\left(r_{1 j}, r_{2 j}, \ldots, r_{n j}\right)$. We can get the corresponding equivalent matrix:

$$
R=\left|\begin{array}{cccc}
r_{11} & r_{12} & \cdots & r_{1 m} \\
r_{21} & r_{22} & \cdots & r_{2 m} \\
\cdots & \cdots & \cdots & \cdots \\
r_{n 1} & r_{n 2} & \cdots & r_{n m}
\end{array}\right| .
$$

\subsubsection{Establishment of Multi-Objective Programming (MP) Model}

If $m$ evaluation index weight vectors $W=\left(w_{1}, w_{2}, \ldots, w_{m}\right)^{T}$, and the final evaluation value of the $i$ th industry for $U_{i}$,

$$
U_{i}=\sum_{j=i}^{m} w_{j} r_{i j}
$$


According to the idea of the maximum entropy and the corresponding equivalent index, we can set up the goal programming equation:

$$
\begin{gathered}
(\mathrm{MP}) \max \left\{-\sum_{i=1}^{n} w_{i} \ln w_{i}\right\}, \\
(\mathrm{MP}) \min \sum_{i=1}^{n} f_{i}(w)=\sum_{i=1}^{n} \sum_{j=1}^{m} w_{j}\left(1-r_{i j}\right)^{2} .
\end{gathered}
$$

Constraint conditions for

$$
\begin{gathered}
\sum_{j=1}^{m} w_{j}=1, \quad w_{j} \geq 0, j=1,2, \ldots, m, \\
w_{i}>w_{k}, \quad 1 \leq i, k \leq m, i \neq m .
\end{gathered}
$$

For the solution of type (4.10)-(4.12) multi-objective programming function, researchers will structure the following mathematical model as (4.13)

$$
\begin{array}{ll}
\min & \delta \sum_{i=1}^{n} \sum_{j=1}^{m} w_{j}\left(1-r_{i j}\right)^{2}+(1-\delta)+\sum_{j=1}^{m} w_{j} \ln w_{j}, \\
\text { s.t. } & \sum_{j=1}^{m} w_{j}=1, w_{j} \geq 0, j=1,2, \ldots, m, \\
& 0 \leq \delta \leq 1 .
\end{array}
$$

For the solution of type (4.13), we will structure Lagrange function:

$$
F(w, \lambda)=\delta \sum_{i=1}^{n} \sum_{j=1}^{m} w_{j}\left(1-r_{i j}\right)^{2}+(1-\delta)+\sum_{j=1}^{m} w_{j} \ln w_{j}-\lambda\left(\sum_{j=1}^{m} w_{j}-1\right) .
$$

According to a necessary condition for the extreme existence, we can get

$$
\begin{gathered}
\frac{\partial F}{\partial w_{j}}=\delta \sum_{i=1}^{n}\left(1-r_{i j}\right)^{2}+(1-\delta)\left(\ln w_{j}+1\right)-\lambda=0, \quad j=1,2, \ldots, m, \\
\frac{\partial F}{\partial \lambda}=\sum_{j=1}^{m} w_{j}-1=0 .
\end{gathered}
$$


Next get

$$
w_{j}=\frac{\exp \left\{-\left[1+\delta \sum_{i=1}^{n}\left(1-r_{i j}\right)^{2} /(1-\delta)\right]\right\}}{\sum_{j=1}^{m} \exp \left\{-\left[1+\delta \sum_{i=1}^{n}\left(1-r_{i j}\right)^{2} /(1-\delta)\right]\right\}}, \quad j=1,2, \ldots, m
$$

Through changing $\delta$ values for the many different results of empowerment choose a group result that most conforms to the formula (4.17) of the combination of empowerment, and get $w_{j}, j=1,2, \ldots, m$ of the empowerment results of formula (4.12) and (4.13). Then based on the industry's index, find out the industrial appraisal value:

$$
U_{i}=\sum_{j=1}^{m} w_{j} r_{i j}
$$

We will order and choose strategic emerging industry according to the size of the $U_{i}$.

\section{Conclusions}

It is a theoretical and practical significance to make the scientific and accurate selection and evaluation of regional strategic emerging industry. This paper tried to use the fuzzy optimization theory and the maximum entropy to select the central and sustainable development industry of area as the regional strategic emerging industry.

First, the paper depends on the aid of the industrial structure similarity coefficient to measure the area of industrial isomorphism, thus gives system dynamically the judgment of the regional industrial structure convergence change characteristics and determines the regional industrial structure from the macroscopic perspective preliminary.

Secondly, it establishes and optimizes fuzzy evaluation model. The problem in view of regional strategic emerging industry selection is influenced by multiple factors and belongs to multistage comprehensive evaluation problem. We can use the method of fuzzy mathematics comprehensive evaluation, but we also need to optimize and improve multistage fuzzy comprehensive evaluation model, so that the evaluation results will be as accurate and objective as possible.

Thirdly, it evaluates the chosen results. We calculate the quotient of location to find out whether the area industry has advantage in the same industry of country. We will calculate intersection to the two kinds of industry and confirm the area strategic emerging industry.

In the future, we will also do empirical analysis based on these models. In addition, we will be coupled to an evaluation about the traditional industries and the strategic emerging industries, including double coupling relevance and developmental evaluation.

\section{Acknowledgment}

This research was partially supported by the National Natural Science Foundation of China (Grant numbers: 71173060, 70773028, and 71031003). 


\section{References}

[1] P. R. Brown, V. E. Soybel, and C. P. Stickney, "Achieving comparability of US and Japanese financial statement data," Japan and The World Economy, vol. 5, no. 1, pp. 51-72, 1993.

[2] C. Perez, "The double bubble at the turn of the century: technological roots and structural implications," Cambridge Journal of Economics, vol. 33, no. 4, pp. 779-805, 2009.

[3] H. Liu, "China's emerging industry strategic principle of selecting and cultivating policy orientation study," Public Understanding of Science, vol. 3, pp. 87-92, 2011.

[4] Y. Hu and J. Zhao, "The application of factor analysis to the choice of strategic new industry," Journal of Social Science Series, vol. 6, pp. 127-129, 2010.

[5] Z. He, R. W. kurz, Geissler k, and Z. Zhou, "Strategic emerging industry choice and evaluation and empirical analysis," Public Understanding of Science, no. 12, pp. 62-67, 2010.

[6] H. Li, "Regional strategic emerging industry selection evaluation," Journal of North China Water Conservancy and Hydropower College, no. 4, pp. 91-93, 2011.

[7] D.-S. Gong, ". Strategic emerging industries, the establishment of the evaluation index system based on the analysis of the industrial characteristics and thinking," Journal of City Economy, vol. 1, pp. 7-9, 2012.

[8] S. Qing, "AHP method in Henan province strategic emerging industry evaluation and selection of decision analysis," Journal of Henan College of Engineering, no. 1, pp. 45-48, 2011.

[9] Z. Qiao, H. Chu, and Y. Wu, "Based on the grey relation analysis of strategic emerging industry evaluation-the biological medicine as an example," Journal of Mathematical Economics, no. 3, pp. 6267, 2010.

[10] Z. Hu, C. Li, and Y. Xiong, "Based on the AHP-IE-PCA, 'combination weighting method of strategic emerging industry selection model'," Public Understanding of Science, no. 7, pp. 104-110, 2011.

[11] V. Pareto, Manuale Di Economic Politiea, Societ a Editrice Linraria, Milano, Italy, 1906.

[12] V. Neumann and O. Morgenstern, Theory of Games and Economic Behavior, Princetion University Press, NJ, USA, 1944.

[13] T. C. Koopmans, "Analysis of production as an efficient combination of activities," in Activity Analysis of Production and Alloeation, T. C. KooPmans, Ed., vol. 13, pp. 33-97, Cowles Commission Monograph, John Wiley \& Sons, New York, NY, USA, 1951.

[14] H. W. Kuhn and A. W. Tucker, "Nonlinear analysis," in Proceeding of the 2d Berley Symposium on Mathematical Statistics and Probability, pp. 481-492, University of California Press, Calif, USA.

[15] G. Debreu, "Representation of a preference ordering by numerical function," in Decision Processes, R. M. Thrall, C. H. Coombs, and R. L. Davis, Eds., pp. 159-165, John Wiley \& Sons, New York, NY, USA, 1954.

[16] L. Harwicz, "Programming in linear spaces," in Studies in Linear and Nonlinear Programming, K. J. Arrow, L. Harwicz, and H. Uzawa, Eds., pp. 38-102, Standford University Press, Calif, USA, 1958.

[17] Z. Johnsen, Studies in Multi Objective Decision Models, Economic Research Center in Lund, Lund, Sweden, 1968.

[18] R. E. Bellman and L. A. Zadeh, “Decision-making in a fuzzy environment," Management Science, vol. 17, pp. B141-B164, 1970.

[19] Z. Wang and H. Wang, "Interregional industry transfer the power of the formation," Journal of Dalian University of Technology, no. 1, pp. 22-26, 2007.

[20] T. Zhang and J. Li, "Application of multi-step fuzzy comprehensive evaluation," Journal of Harbin Engineering University, vol. 3, pp. 132-135, 2002.

[21] L. Shi, M. Ju, Z. Li, and M. Chen, "Application of regional environmental impact assessment with fuzzy mathematics method," http://www.paper.edu.cn/.

[22] Y. Li, Z. Gao, and Y. Han, "The determination of weight value and the choice of composite operators in fuzzy comprehensive evaluation," Computer Engineering and Applications, vol. 23, pp. 38-43, 2006. 


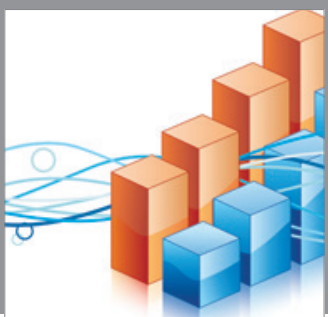

Advances in

Operations Research

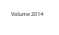

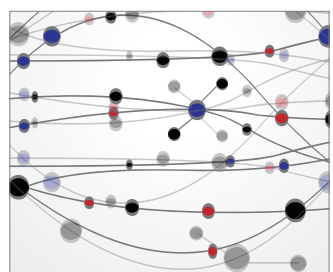

\section{The Scientific} World Journal
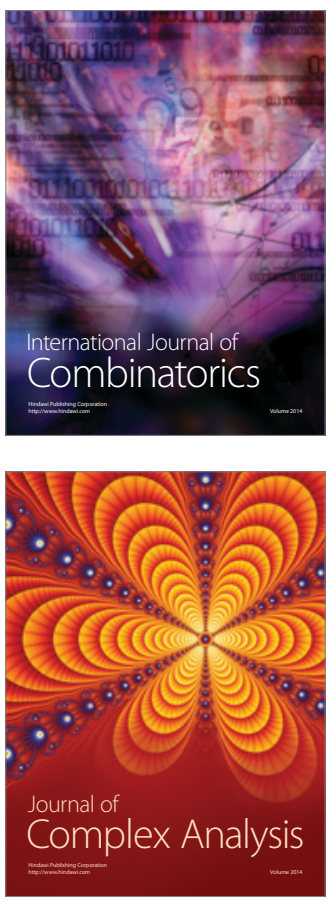

International Journal of

Mathematics and

Mathematical

Sciences
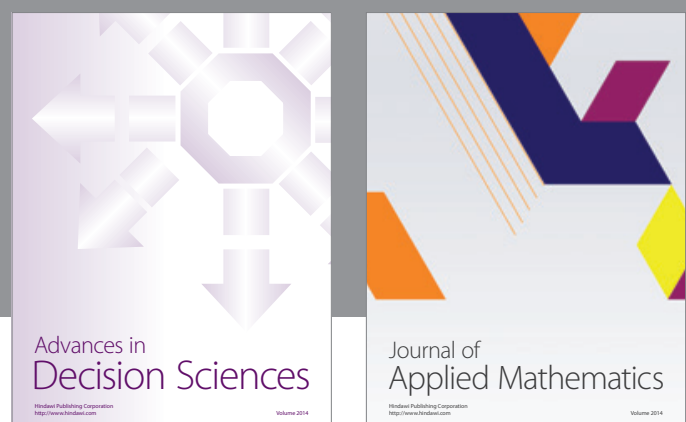

Journal of

Applied Mathematics
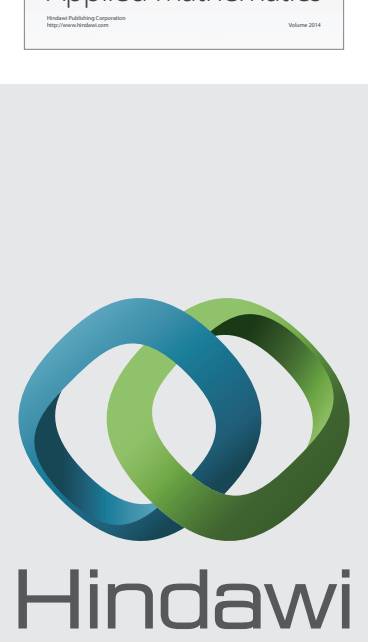

Submit your manuscripts at http://www.hindawi.com
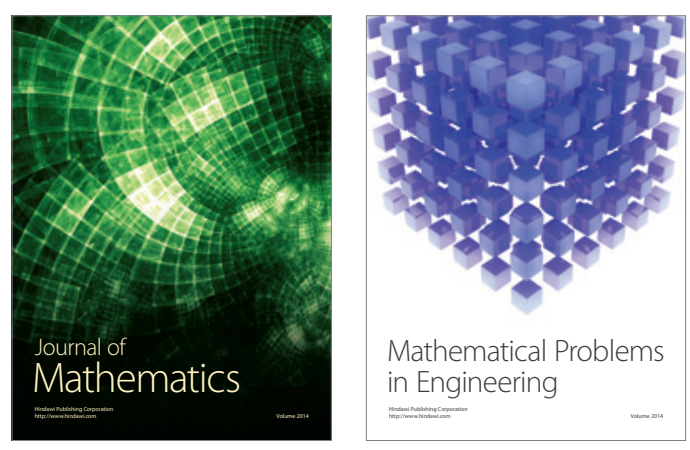

Mathematical Problems in Engineering
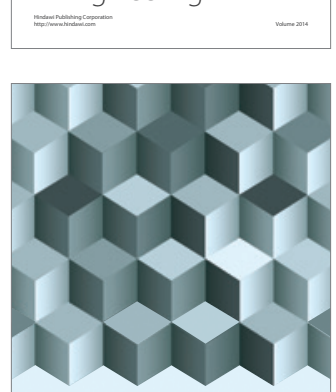

Journal of

Function Spaces
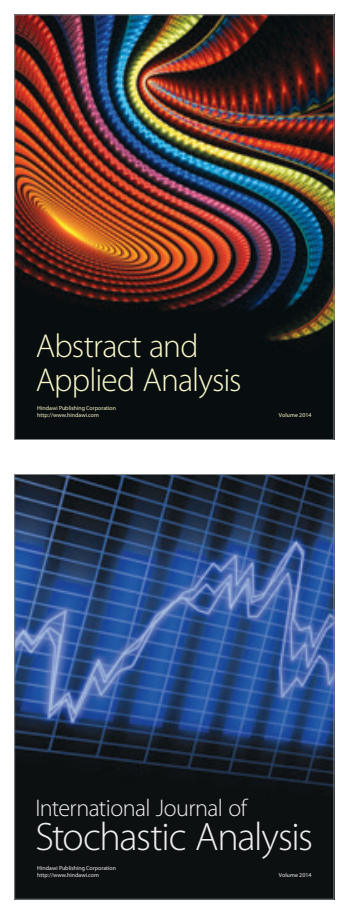

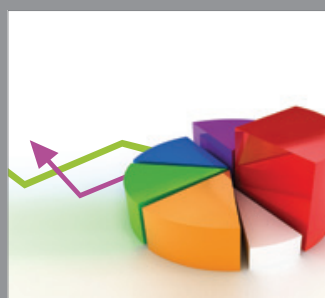

ournal of

Probability and Statistics

Promensencen
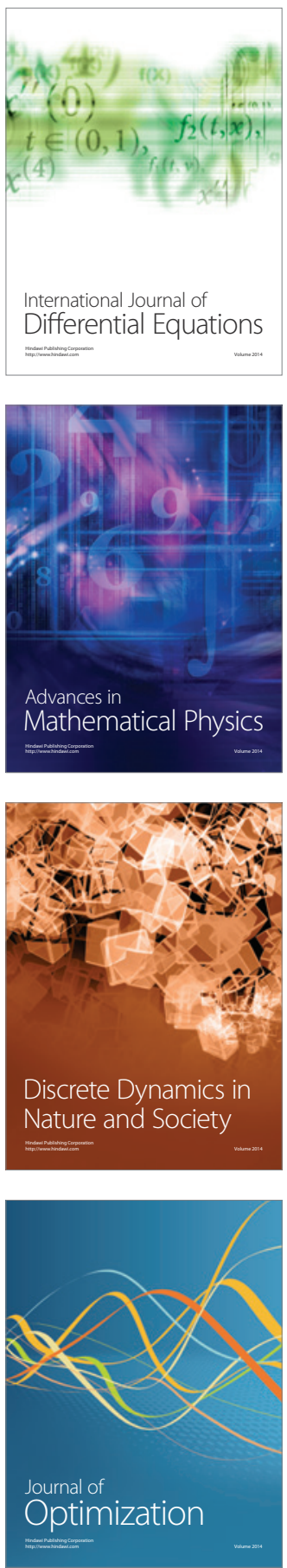